\title{
ИНФОРМАЦИОННАЯ МОДЕЛЬ ПОТЕНЦИАЛЬНО ВЗРЫВООПАСНОГО ОБЬЕКТА. ЧАСТЬ 3
}

\author{
Волков В.Э., канд. физ.-мат. наук, доцент \\ Одесская национальная академия пищевых технологий, Одесса
}

\begin{abstract}
Аннотация: Произвольный потенциильно взрывоопасный объект рассмотрен с позиций системного анализа как сложная иерархическая система. Произведен последний этап разработки информационной модели этой системь - построена диаграмма ее информационной структуры.

Annotation: Arbitrary potentially explosive object is considered from the point of view of the system analysis as the complex hierarchical system. The last stage of elaboration of the information model for this complex system is fulfilled: the diagram of its information structure is built.
\end{abstract}

Ключевые слова: потенциально взрывоопасный объект, сложная система, информационная модель.

В предыдущих работах [1,2] нами рассмотрен произвольный потенциально взрывоопасный объект (ПВОО), который с позиций системного анализа [3] является сложной иерархической системой. В качестве первых двух этапов разработки информационной модели этой системы произведено ее структурирование [1] и идентификация концептуальных сущностей [2], или объектов, которые составляют подсистему для анализа [4,5]. На следующем этапе разработки информационной модели системы необходимо создать (в самом общем виде) графическое изображение сложного ПВОО (СПВОО), состоящего из элементарных ПВОО (ЭПВОО).

Графическое изображение СПВОО, состоящего из различных ЭПВОО, в самом общем виде показано на Рис. 1. Атрибуты ID B_ЭПВОО и ID ОВ_ЭПВОО имеют в данном случае следующий смысл: под В_ЭПВОО (OB_ЭПВОО) понимается наиболее взрывоопасный (относительно взрывоопасный) объект среди всех объектов всех 7-ми выделенных выше классов ЭПВОО, а не только среди всех экземпляров объекта данного класса (как это имеет место выше). Таким образом, значение атрибута ID B_ЭПВОО (ID OB_ЭПВОО) определяется по

максимальному значению величины $\tilde{B}(\tilde{O B})$ из значений атрибута Взрывоопасность (Относительная взрывоопасность) для взрывоопасных (относительно взрывоопасных) открытого пространства, бесконечного, полуоткрытого и открытого канала, бесконечной, полуоткрытой и открытой трубы. Значение атрибута Взрывоопасность В_ЭПВОО равно значению атрибута Взрывоопасность того ЭПВОО, который является наиболее взрывоопасным (этот ЭПВОО идентифицируется как ID B_ЭПВОО, для него нечеткая логическая величина $\tilde{B}$ принимает максимальное значение среди всех ЭПВОО, составляющих в совокупности СПВОО). Значение атрибута Пожароопасность В_ЭПВОО равно значению атрибута Пожароопасность наиболее взрывоопасного ЭПВОО. Значение атрибута Относительная взрывоопасность В_ЭПВОО равно значению атрибута Относительная взрывоопасность того ЭПВОО, который является наиболее относительно взрывоопасным (этот ЭПВОО идентифицируется как ID OB_ЭПВОО, для него нечеткая логическая величина

$\tilde{O B}$ принимает максимальное значение среди всех ЭПВОО, составляющих в совокупности СПВОО). Значение атрибута Взрывоопасность СПВОО равно значению атрибута Взрывоопасность В_ЭПВОО. Значение атрибута Относительная взрывоопасность СПВОО равно значению атрибута Относительная взрывоопасность В_ЭПВОО. Очевидно, что для подавляющего большинства конкретных СПВОО в составе СПВОО представлены ЭПВОО не всех 7-ми классов, а только некоторых из них. Например, ЭПВОО класса 1 (Открытое пространство) при моделировании реального конкретного СПВОО применяется относительно редко. СПВОО непосредственно участвует в следующих связях:

R1: СПВОО - Взрывоопасное открытое пространство;

R2: CПВОО - Относительно взрывоопасное открытое пространство;

R3: CПВОО - Взрывоопасный бесконечный канал;

R4: CПВОО - Относительно взрывоопасный бесконечный канал;

R5: CПВОО - Взрывоопасный полуоткрытый канал;

R6: CПВОО - Относительно взрывоопасный полуоткрытый канал;

R7: CПВОО - Взрывоопасный закрытый канал;

R8: CПВОО - Относительно взрывоопасный закрытый канал;

R9: CПВОО - Взрывоопасная бесконечная труба; 


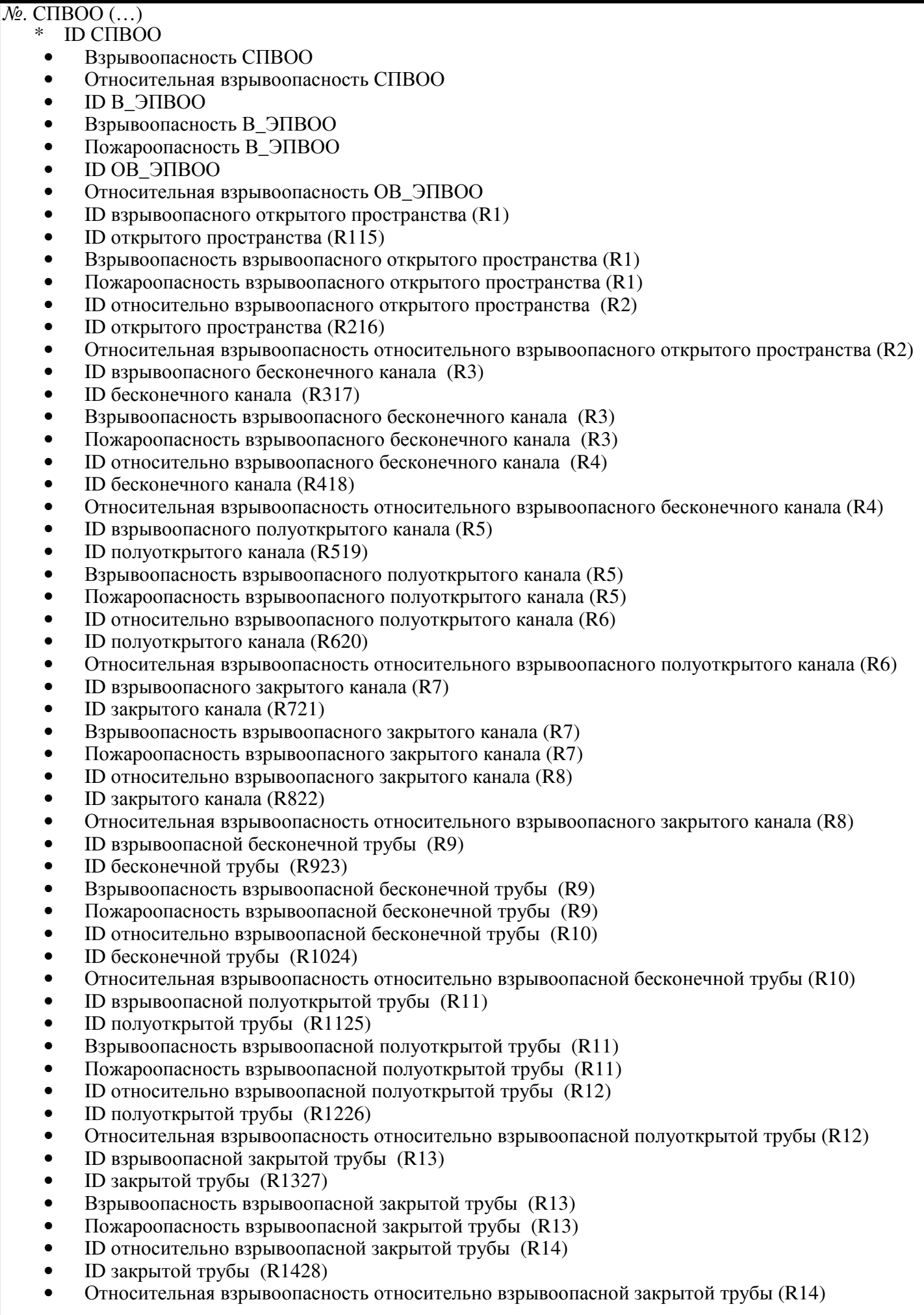

Рис. 1. Графическое изображение СПВОО в общем виде 
R10: CПВОО - Относительно взрывоопасная бесконечная труба;

$\mathrm{R} 11: \mathrm{CПBOO} \mathrm{-} \mathrm{Взрывоопасная} \mathrm{полуоткрытая} \mathrm{труба;}$

R12: CПВОО - Относительно взрывоопасная полуоткрытая труба;

R13: CПВОО - Взрывоопасная закрытая труба;

R14: CПВОО - Относительно взрывоопасная закрытая труба.

Для всех перечисленных выше связей СПВОО содержит объект, указанный справа , после «-»; этот объект, в свою очередь, содержится в СПВОО. Все перечисленные связи являются связями 1:1 в безусловной форме. Атрибуты СПВОО, где в скобках стоят идентификаторы связей R1,.., R14, являются вспомогательными атрибутами СПВОО, формализующими эти связи.

Взрывоопасное открытое пространство участвует в следующей связи:

R15: Взрывоопасное открытое пространство - Открытое пространство.

Связь R15 организована по образцу [2] (Взрывоопасное открытое пространство - в роли В_ЭПВОО, Открытое пространство - в роли ЭПВОО); связь является условной связью 1:1.

Относительно взрывоопасное открытое пространство участвует в следующей связи:

R16: Относительно взрывоопасное открытое пространство - Открытое пространство.

Связь R16 организована также по образцу [2] (Относительно взрывоопасное открытое пространство - в роли ОВ_ЭПВОО, Открытое пространство - в роли ЭПВОО); связь является условной связью 1:1.

Аналогично связи R15 имеют место следующие связи:

R17: Взрывоопасный бесконечный канал - Бесконечный канал;

R19: Взрывоопасный полуоткрытый канал - Полуоткрытый канал;

R21: Взрывоопасный закрытый канал - Закрытый канал;

$\mathrm{R} 23$ : Взрывоопасная бесконечная труба - Бесконечная труба;

R25: Взрывоопасная полуоткрытая труба - Полуоткрытая труба;

$\mathrm{R} 27$ : Взрывоопасная закрытая труба - Закрытая труба.

Аналогично связи R16 имеют место следующие связи:

R18: Относительно взрывоопасный бесконечный канал - Бесконечный канал;

R20: Относительно взрывоопасный полуоткрытый канал - Полуоткрытый канал;

R22: Относительно взрывоопасный закрытый канал - Закрытый канал;

R24: Относительно взрывоопасная бесконечная труба - Бесконечная труба;

R26: Относительно взрывоопасная полуоткрытая труба - Полуоткрытая труба;

R28: Относительно взрывоопасная закрытая труба - Закрытая труба.

Как неизбежное логическое следствие существования связей R1 и R15 образуется связь R115. Связь R115 является композицией [5] связей R1 и R15 (R115=R1+R15). Графически эта связь изображена на Рис. 2; связь является условной связью 1:1.

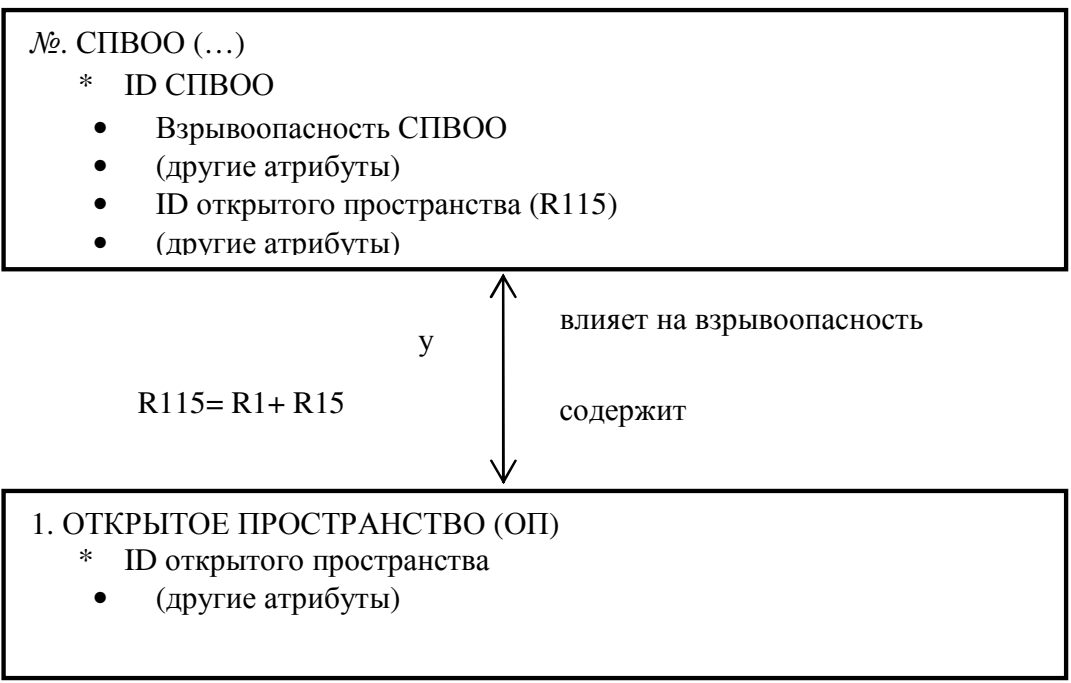

Рис. 2. Связь R115 СПВОО и ЭПВОО класса Открытое пространство 
Как неизбежное логическое следствие существования связей R2 и R16 образуется связь R216. Связь R216 является композицией связей R2 и R16 (R216=R2+R16). Графически эта связь изображена на Рис. 3; связь является условной связью 1:1.

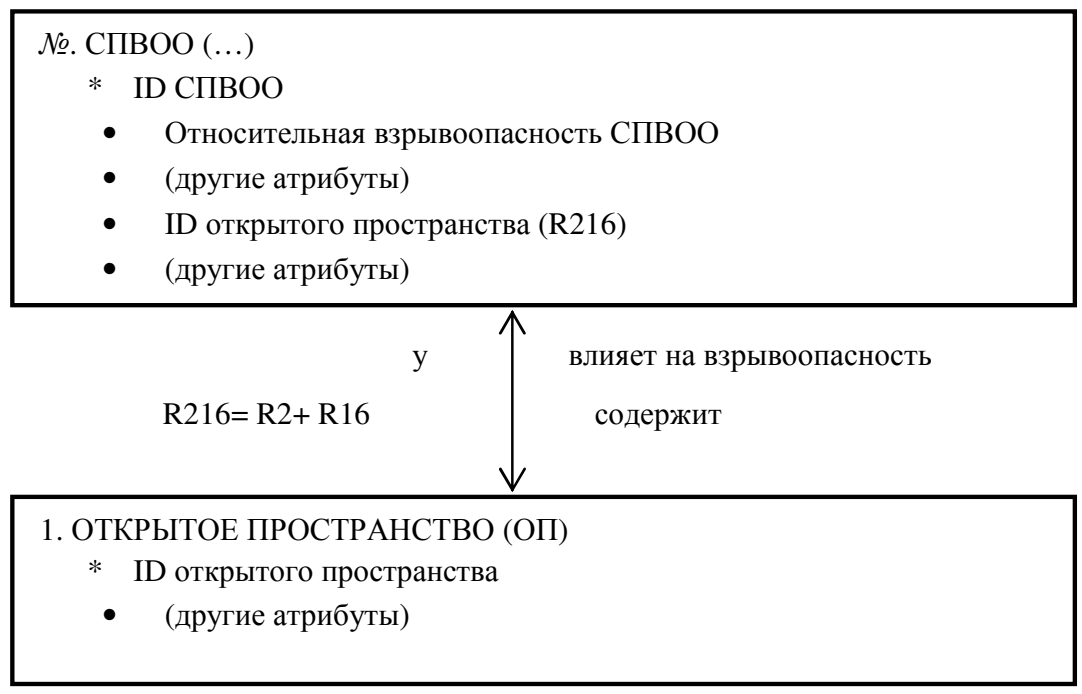

\section{Рис. 3. Связь R216 СПВОО и ЭПВОО класса Открытое пространство}

Аналогично имеют место следующие связи СПВОО и ЭПВОО различных классов:

R317: CПВОО - Бесконечный канал; R317=R3+R17;

R418: CПВОО - Бесконечный канал; R418=R4+R18;

R519: CПВОО - Полуоткрытый канал; R519=R5+R19;

R620: CПВОО - Полуоткрытый канал; R620=R6+R20;

R721: CПВОО - Закрытый канал; R721=R7+R21;

$\mathrm{R} 822: \mathrm{CПBOO} \mathrm{-} \mathrm{Закрытый} \mathrm{канал;} \mathrm{R822=R8+R22;}$

R923: CПВОО - Бесконечная труба; R923=R9+R23;

R1024: CПВОО - Бесконечная труба; R1024=R10+R24;

$\mathrm{R} 1125$ : СПВОО - Полуоткрытая труба; R1125=R11+R25;

R1226: CПВОО - Полуоткрытая труба; R1226=R12+R26;

R1327: CПВОО - Закрытая труба; R1327=R13+R27;

R1428: CПВОО - Закрытая труба; R1428=R14+R28.

Связи R317, R519, R721, R923, R1125 и R1327 аналогичны связи R115 (Рис. 2). Связи R418, R620, R822, R1024, R1226 и R1428 аналогичны связи R216 (Рис. 3).

Так как все объекты с их атрибутами и все связи между объектами описаны, можно сформировать в общем виде информационную модель произвольного сложного потенциально взрывоопасного объекта (СПВОО).

Для информационной модели любой подсистемы основным рабочим продуктом является диаграмма информационной структуры [5]. Диаграмма информационной структуры есть графическое представление информационной модели (иногда диаграмму информационной структуры и называют информационной моделью).

На Рис. 4 показан общий вид диаграммы информационной структуры произвольного СПВОО. Использованы следующие сокращения:

В_ОП - ВЗРЫВООПАСНОЕ ОТКРЫТОЕ ПРОСТРАНСТВО,

OВ_ОП - ОТНОСИТЕЛЬНО ВЗРЫВООПАСНОЕ ОТКРЫТОЕ ПРОСТРАНСТВО,

В_3Т - ВЗРЫВООПАСНАЯ ОТКРЫТАЯ ТРУБА,

В_ЗТ - ОТНОСИТЕЛЬНО ВЗРЫВООПАСНАЯ ОТКРЫТАЯ ТРУБА.

Использована также нумерация: 0 - для СПВОО, 11 - для В_ОП, 12 - для ОВ_ОП, ..., 3в1 - для В_3Т, 3в2 для OB_3T, ..., 1 - для открытого пространства, .., Зв - для закрытой трубы. 


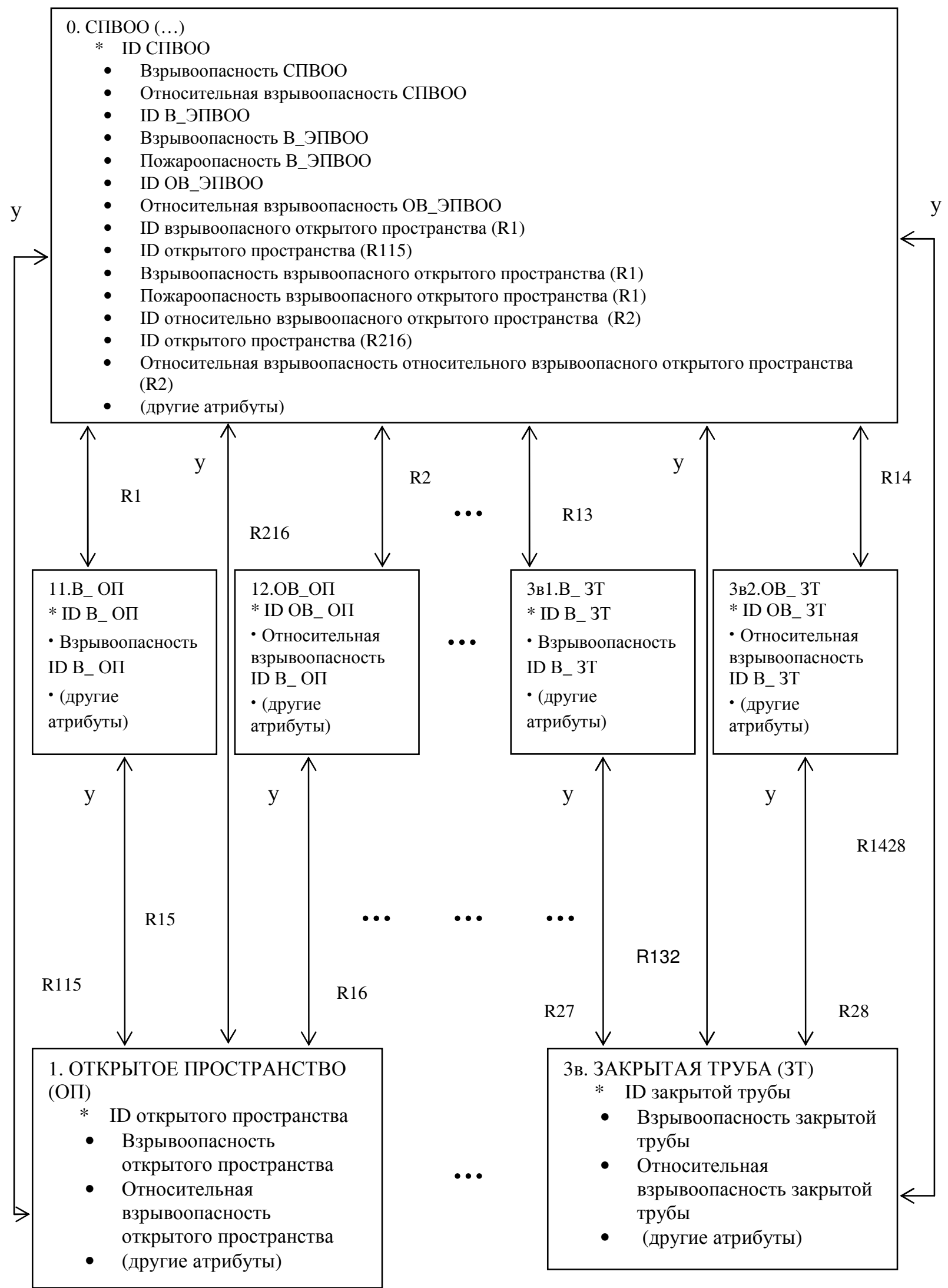

Рис. 4. Диаграмма информационной структуры СПВОО 
Естественно, что информационная модель (и, соответственно диаграмма информационной структуры) для конкретного СПВОО значительно проще и естественней, чем для описанного выше абстрактного СПВОО, имеющего некоторый общий (произвольный) вид.

\section{Выводы}

Таким образом, создано (в самом общем виде) графическое изображение СПВОО, состоящего из различных ЭПВОО, а также построена диаграмма информационной структуры СПВОО, являющаяся графическим представлением информационной модели этого объекта.

\section{Литература}

1. Волков В.Э. Информационная модель потенциально взрывоопасного объекта. Часть 1 //Автоматизация технологических и бизнес-процессов, 2012. - №№9-10, июнь 2012. - С. 3-11.

2. Волков В.Э. Информационная модель потенциально взрывоопасного объекта. Часть 1 //Автоматизация технологических и бизнес-процессов, 2012. - №№11-12, декабрь 2012. - С. 3-9.

3. Ладанюк А.П. Основи системного аналізу: Навч. посібник. - Вінниця: Нова книга, 2004. - 176 с.

4. Объектно-ориентированный анализ и проектирование с примерами приложений / Г. Буч, Р.А. Максимчук, М. У. Энгл и др. - М: ООО «И.Д. Вильямс», 2008. - 720 с.

5. Шлеер С., Меллор С. Объектно-ориентированный анализ: Моделирование мира в состояниях. - К.: Диалектика, 1993. - 240 с.

\section{НО НОВОСТИ АВТОМАТИЗАЦИИ}

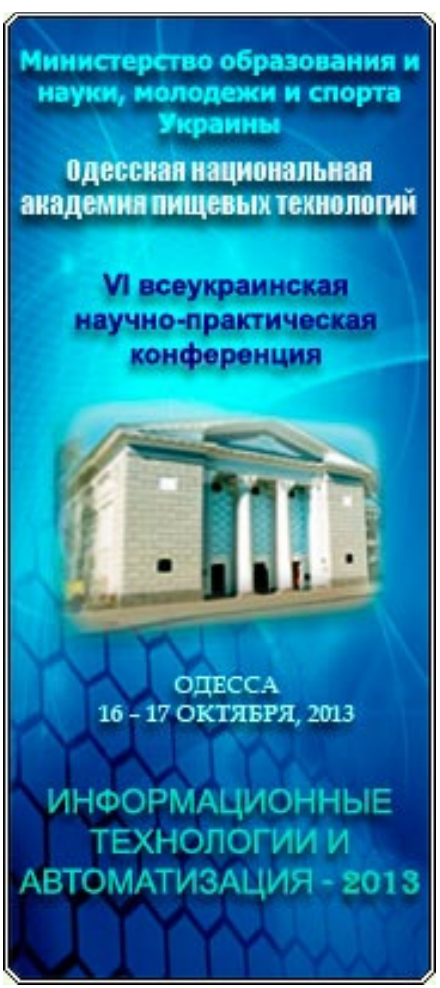

16-17 октября 2013 г. на базе Одесской национальной академии пищевых технологий состоится VI-я Всеукраинская научнопрактическая конференция «Информационные технологии и автоматизация - 2013» Организаторы конференции: Министерство образования и науки Украины Одесская национальная академия пищевых технологий при поддержке «Одесской областной государственной администрации», «Представительства фирмы Moeller в Украине»

Для участия в конференции приглашаются ученые, инженеры, специалисты в области автоматизации, программисты, аспиранты, студенты. Приглашаем к сотрудничеству национальных и международных спонсоров.

$\begin{array}{ll}\text { Телефоны для справок: } & +380-48-712-41-30, \\ & +380-48-712-41-15, \\ & +380-48-712-41-92, \\ & +380-48-712-41-57 . \\ \text { Телефон/факс: } & +380-48-724-86-72 .\end{array}$

ПРИГЛАШАЕМ! 